INTRODUCTION TO COLPOSCOPY-A DIagnostic Aid in Benign and Preclinical Cancerous Lesions of the Cervix Uteri-Karl A. Bolten, M.D., Gynecologist and Research Associate, Dept. of Pathology, Subdivision Obstetric and Gynecologic Pathology, University of Oklahoma, School of Medicine. Cooperating in Pathology, William E. Jaques, M.D., Chairman and Professor of Pathology, University of Oklahoma, School of Medicine; with Forewords by Joe Vincent Meigs, M.D., and Daniel W. Goldman, M.D. Grune \& Stratton, Inc., 381 Fourth Avenue, New York 16 , N. Y., 1960. 76 pages, $\$ 7.75$

This slender volume is an effort to revive interest in a diagnostic procedure which many gynecologists abandoned 25 to 30 years ago, largely because of the difficulty in interpretation of the bizarre patterns seen on the distal end of the cervix. Despite the author's enthusiasm for the colposcope, it seems unlikely that it will prove more helpful than conization of the cytologically positive cervix to detect carcinoma in situ.

However, for those with a desire to know more about the colposcope and how to use it, Bolten's monograph can be recommended. In addition to the technical aspects, there are descriptions of what one may see in the presence of various benign and malignant processes involving the cervix and vagina. Approximately half the book is devoted to illustrations-of the instrument and accessories, copies of drawings from an atlas by Mestwerdt, colored photographs of cervices (mostly contributed by Wespi from Switzerland), and a few histopathologic photomicrographs. There is also a list of 127 references, but this contains many duplications, owing to the unconventional manner in which reference numbers are used throughout the text.

This book is beautifully printed on paper of excellent quality, and for the most part the illustrations are very good. Some of the black and white photomicrographs leave something to be desired, but this appears not to be the fault of the printer. The price seems high for so few pages, but one must presume that illustrations in color are costly.

C. E. McLennan, M.D.

STETRICS EVALUATION OF THE PELVIS IN OB. Mdition - Charles M. Steer, M.D., Med.Sc.D., F.A.C.S., F.A.C.O.G., Associate Professor of and Surgeons, Clinical Obstetrics and Gynecology, College of Physicians pital for Women. W. B. Saunders Company, Philadelphia, 1959. 131 pages, $\$ 4.00$.

The second edition of this outstanding monograph has been very well written by Dr. Steer. The anatomy of the pelvis and the classification of the various types of pelves are very clearly and very accurately described. A thorough con. sideration of the details of the clinical examination of the pelvis is included.

In his discussion of the significance and usefulness of an accurate knowledge of the pelvis Dr. Steer takes a very realistic view. He describes in detail the mechanism of labor and in particular the type of engagement noted in the various types of pelves. He emphasizes, for example, the increase in posterior positions with android and anthropoid pelves. From this he proceeds logically to a discussion of the treatment of pelvic arrest with forceps in the different types of pelves and gives an excellent discussion of the proper forceps maneuvers to be employed.

Dr. Steer states that $\mathrm{x}$-ray pelvimetry should be performed only in those cases in which clinical evidence of disproportion exists and that this will be true in not over 10 per cent of patients. He feels that pelvimetry should be obtained after the onset of labor and describes the technique to be employed. He wisely states that $x$-ray examination provides only a statistical statement of the probability of serious arrest and that this can then be used as one factor in determining the best method of delivery.
The summary at the end of the last chapter is excellent. Here the author mentions the facts that some patients with high degrees of disproportion do deliver spontaneously and that in some clinics pitocin infusion is being used to overcome disproportion. However, he cites possible dangers to the child under these circumstances. On the other hand, he decries the excessive use of cesarean section when one is not certain that disproportion exists and states that use of $\mathbf{x}$-ray pelvimetry is the only way to be certain.

In this second edition Dr. Steer has amplified the discussion of the use of forceps in overcoming arrest and makes many very helpful and practical suggestions. The number of patients who have been surveyed has been greatly increased during the eight years which have elapsed since the publication of the first edition. This permits a more detailed consideration and more significant conclusion regarding the probability of difficult delivery with a given amount of disproportion.

In my opinion this is an excellent monograph which should be thoroughly perused by all men in training in obstetrics and gynecology. It makes interesting reading too for those of more experience who must critically review periodically their own feelings about the principles of management of the patient having a difficult labor.

\section{* * *}

PSYCHIATRY: DESCRIPTIVE AND DYNAMIC-Jackson A. Smith, M.D., F.A.C.P., Clinical Director, Illinois State Psychiatric Institute, Chicago, Illinois. The Williams $\&$ Wilkins Company, Baltimore 2, Maryland, 1960. 342 pages, $\$ 7.00$.

The increasing burden of knowledge of psychological behavior and the application of medical techniques to the field of psychiatry leads to two major issues. One is that of communication of this knowledge to the nonpsychiatric physician, and the other a real difficulty in trying to trans. late such knowledge into more general terms. This book represents a further attempt to bridge these gaps and to lay out as clearly as possible the findings of psychiatry so that they may be utilized by any practitioner.

The text includes good explanations of the history and the schools of psychiatry, as well as a clear, current exposition of psychodynamics and the psychiatric examination. The bulk of the material of the book is taken up with the various reactions which are seen in current psychiatric practice. It is felt that the author has somewhat more of an emphasis on hysteria and hysterical phenomena than he does on other reactions, but in general there are clear pictures of schizophrenia, of the affective reactions, and certain neurotic pictures. It is felt that there could be an expansion, for the purpose of the book, of the material concerned with the psychophysiological disturbances, since such psychosomatic reactions make up a large bulk of nonpsychiatric practice.

There is, however, a good section on child psychiatry for the general practitioner.

One criticism of this book is found in the rather abrupt manner in which all topics are presented. The writer is extremely forceful, and sometimes his forcefulness leads to an overstatement of dynamic material in comparison to a more conservative approach. There is obvious evidence that the writer is not impressed with many dynamic formulations, and the thinly veiled cynicism with which his ideas are expounded sometimes seems out of place in a general textbook.

With these limitations, however, the material, particularly in certain areas, is good. If, as has been noted, the psychodynamics of the psychosomatic conditions could be expanded, it would become indeed a rather valuable textbook. HENRY H. WORK, M.D. 